\title{
New Economic Geography After Thirty Years
}

\author{
Steven Brakman, Harry Garretsen, and Charles van Marrewijk
}

\section{Contents}

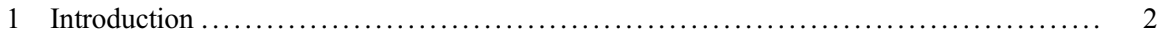

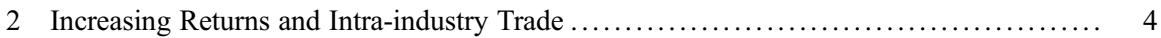

2.1 Basic Ingredients of the Model ........................................ 4

2.2 The Home Market Effect as a Volume Effect .............................. 6

2.3 The Home Market Effect as a Factor Price Effect .......................... 10

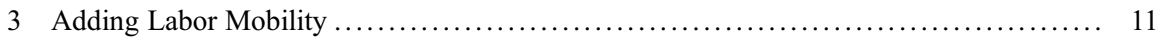

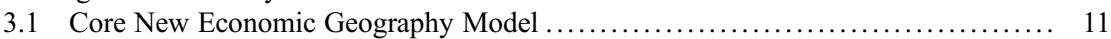

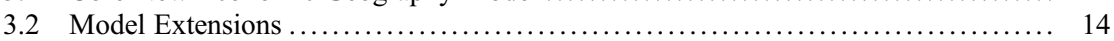

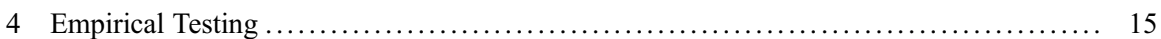

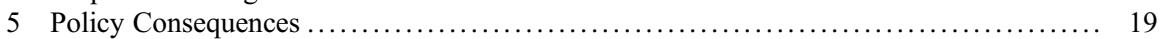

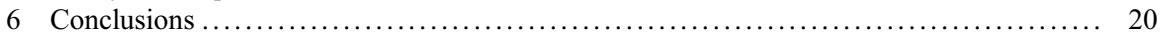

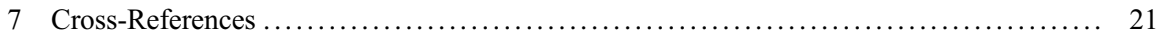

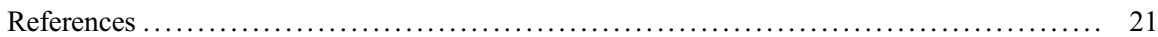

\begin{abstract}
In this chapter we briefly discuss how the New Economic Geography literature follows from and builds on international trade theory. We then turn to the main empirical implications of New Economic Geography. We highlight that the main problem with empirical applications of New Economic Geography is that a single test of the implications of the model is illusive because of the structure of the model. As a result, the main consequences of the model are usually tested separately. Some of the implications of the model are also consistent with other models, notably models in urban economics. We stress therefore, that despite an
\end{abstract}

\footnotetext{
S. Brakman $(\bowtie) \cdot H$. Garretsen

Faculty of Economics and Business, University of Groningen, Groningen, The Netherlands e-mail: s.brakman@rug.nl; j.h.garretsen@rug.nl

C. van Marrewijk

Utrecht University School of Economics, Utrecht, The Netherlands

e-mail: J.G.M.vanMarrewijk@uu.nl
} 
initial surge in empirical research inspired by New Economic Geography as well as improved methods, the empirical evidence still remains rather sketchy. Moreover, up to now policy advise based on New Economic Geography is mostly qualitative.

\section{Keywords}

Transport cost $\cdot$ Large market $\cdot$ Nominal wage $\cdot$ Home market effect $\cdot$ Shock sensitivity $\cdot$ New economic geography

\section{JEL Classification}

F1 $\cdot$ R1

\section{Introduction}

The Nobel prize committee that awarded the Nobel prize in economics to Paul Krugman in 2008, stressed that the award was essentially given to him for his contributions in (mainly) three papers in two disciplines: international trade and economic geography. The prize committee of the Royal Swedish Academy of Sciences stated in its scientific background report (p. 1): "Traditionally, trade theory and economic geography evolved as separate subfields of economics. More recently, however, they have converged [to] become more and more united through new theoretical insights, which emphasize that the same basic forces simultaneously determine specialization across countries for a given international distribution of factors of production (trade theory) and the long-run location of those factors across countries (economic geography): http://nobelprize.org/nobel_prizes/economics/lau reates/2008/index.html."

Krugman $(1979,1980)$ deal with international trade (notably intra-industry trade), whereas Krugman (1991) extends the analysis of the first two papers by endogenizing the spatial allocation of economic activity. Both contributions became workhorse models for the two disciplines: the monopolistic competition model became the standard international trade reference for models incorporating intraindustry trade and the extension of this model, by allowing for factor mobility, became the core model of New Economic Geography (also known as Geographical Economics, a term we prefer).

Krugman (1991) extended the concept of the spatial equilibrium. According to Glaeser (2008, p. 4), the spatial equilibrium is the "single most important concept in urban or regional economics...if identical people are choosing to live in two different places then those two different places must be offering an equivalent bundle of advantages, like wages, prices and amenities. Essentially, there must be no potential for arbitrage over space."

In urban economics routinely two types of spatial equilibria are distinguished. First, a spatial equilibrium within cities that describes a trade-off between housing costs and transportation costs (the origins of this model goes back to the Von Thunen model). Closer to Central Business districts housing costs are high but commuting 
costs low. In equilibrium these costs are balanced and no one has an incentive to relocate anymore within cities. Second, an equilibrium between cities (Henderson 1974). These models describe a trade-off between increasing returns that rise with city size (higher nominal wages), but increasing city size also increase all sorts of negative externalities, such as congestion, high housing costs, pollution etc. In equilibrium different cities offer identical net wages, that is nominal wages corrected for negative externalities, and in equilibrium no one has an incentive to relocate between cities. Despite the sophistication of the latter type of models, f.i. explaining sector specialization of different cities - they have one big disadvantage; cities are modelled as floating islands. It does not matter were on the map the cities are located. In this sense geography is usually not modelled in models based on Henderson (1974). In Krugman (1991) this omission is tackled head on, and is central in his equilibrium. Cities are interrelated and geography is crucial; it is of fundamental importance where on the map cities are located, and location is associated with transportation costs to the other cities. The price that has to paid for this extension is that different specialization patterns regarding different types of industries are usually not modelled.

In this chapter, and almost 30 years after Krugman (1991), we will highlight the main characteristics of New Economic Geography and in doing so we will not only explain the fundamentals of New Economic Geography and trace its origins to international trade theory, but we also mention some of the more recent developments. Next, we will illustrate the current state of affairs with respect to the empirical evidence for New Economic Geography and, related to this, the policy consequences of the model. Three features stand out. First, the combination of increasing returns to scale, imperfect competition and transport costs gives rise to the so-called Home Market effect. Second, the combination of the Home-market effect with interregional labour mobility endogenizes the location decisions of firms and footloose workers and hence the spatial allocation of both supply and demand. This set-up allows for multiple equilibria, one of which is a core-periphery equilibrium. This explains why the model has also been used in urban economics to explain, for example, a system of cities. Third, despite a large and increasing literature on empirical evidence, a convincing empirical test of New Economic Geography is still missing. This also implies that policy advice based on the model should be handled with care and so far the basic policy contributions of New Economic Geography are of a qualitative nature.

In this chapter we will focus on the three aforementioned issues. A chapter like this is too short to provide a full survey, but the key issues will be introduced and explained (see reference list). In essence, by discussing the three topics, we will stress the most important contributions of New Economic Geography, and explain the tug of war between the agglomeration and spreading forces that are active in the New Economic Geography models and their potential empirical and policy implications. 


\section{Increasing Returns and Intra-industry Trade}

\subsection{Basic Ingredients of the Model}

During the 1970s it became increasingly clear that the standard workhorse models of international trade were at odds with the facts. The Heckscher-Ohlin and the Ricardian model give a rationale for inter-industry trade only. Empirical research (Grubel and Lloyd 1975), however, clearly showed that trade between (developed) countries was mainly in the form of intra-industry trade. The bulk of trade is in similar goods between similar countries, a puzzling phenomenon in neo-classical trade models. The theoretical challenge was to come up with a trade model that allowed for intra-industry trade. A possible explanation should centre on the role of increasing returns to scale and on an imperfect competition in market structure. In Krugman (1979) a simplified version of the monopolistic competition model, as developed by Dixit and Stiglitz (1977), is introduced (see also Dixit and Norman (1980)). The Dixit-Stiglitz model provides a fruitful way to model monopolistic competition. Almost instantly it became the preferred choice of researchers to model monopolistic competition, and it has become the benchmark model in various fields (see for a survey of contributions, Brakman and Heijdra (2004)). We give a simplified version of the model below (The discussion is based on Brakman and Garretsen (2009)).

\subsubsection{Demand}

Household utility is characterized by a love-of-variety effect that assumes that each variety $c_{i}, i=1, \ldots, N$ enters utility $U$ symmetrically as an incomplete substitute, $H$ is a homogeneous commodity which can serve as a numéraire, and $M$ is often referred to as manufacturing:

$$
U=H^{1-\delta} M^{\delta}, \text { where } M=\left(\sum_{i=1}^{N} c_{i}^{\rho}\right)^{1 / \rho} \text { and } 0<\rho \equiv\left(1-\frac{1}{\varepsilon}\right)<1 .
$$

Where $\delta$ is the Cobb-Douglas share of $M$ and $(1-\delta)$ is the Cobb-Douglas share of $H$. The elasticity of substitution between varieties $\varepsilon$ is determined by the parameter $\rho$. If the number of varieties is (very) large, firms consider the elasticity of demand $\varepsilon$ as given. Utility maximization of Eq. (1) subject to the budget constraint gives (For a step by step derivation see Brakman et al. (2019), Chap. 7):

$$
c_{i}=\frac{p_{i}^{-\varepsilon} \delta w L}{\sum_{j=1}^{N} p_{j}^{1-\varepsilon}}
$$

Where $p_{i}$ is the price of variety $i$ and $N$ is the number of varieties. The term in the denominator is related to the price index for the manufactured good. In what follows we assume that there is only one factor of production, labor $L$ with wage rate $w$. 


\subsubsection{Supply}

For the explanation of intra-industry trade, it is necessary that similar goods are produced in different places. Intra-industry trade follows immediately in a multi country setting if all varieties are consumed by all consumers (love of variety effect). A simple way to introduce (internal) economies of scale and ensuring that each variety $i$ is produced by a single firm is via the following labor cost function:

$$
l_{i}=\alpha+\beta x_{i}, \text { where } \alpha, \beta>0 .
$$

Labor $l_{i}$ is the only production factor, which earns a wage $w$. The parameters $\alpha$ and $\beta$ determine the fixed and marginal costs, $\alpha w$ and $\beta w$ respectively (the fixed costs give rise to the internal scale economies). Equation (3) implies that average costs are decreasing in the quantity of variety $i$ that is produced, and this warrants that in the competitive equilibrium a particular variety is produced by the firm that had initially the largest market share and thus the lowest costs per unit of production.

The full-employment condition requires that the summation of Eq. (3) over all varieties equals total labor supply:

$$
L=\sum_{i=1}^{N} l_{i}=\sum_{i=1}^{N}\left(\alpha+\beta x_{i}\right)
$$

Firms are defined symmetrically which implies that $p_{i}=p$ and $x_{i}=x$ for all $i$ in equilibrium. So, the number of varieties, $\mathrm{N}$, in equilibrium can easily be calculated from:

$$
L=N(\alpha+\beta x)
$$

\subsubsection{Equilibrium}

The next step is to derive the market equilibrium. This gives the equilibrium output of each firm $x_{i}$ the equilibrium number of varieties $N$ (and hence the equilibrium number of firms), and it also yields the equilibrium price-wage ratio $p_{i} / w$. Profit maximization gives the familiar mark-up pricing rule, equating marginal costs to marginal revenue (dropping the index because of symmetry):

$$
p=\frac{\varepsilon}{\varepsilon-1} \beta w \text { or } \frac{p}{w}=\frac{\varepsilon}{\varepsilon-1} \beta .
$$

The zero profit condition implies that:

$$
0=p x-(\alpha+\beta x) w \text { or } \frac{p}{w}=\beta+\frac{\alpha}{x}=\beta+\frac{\alpha}{L c_{i}} .
$$

Equations (6) and (7) together give the break-even output $x$ of a firm that is consistent with profit maximization, and free entry and exit into the market: $x=(\varepsilon-1) \alpha / \beta$. 


\subsubsection{International Trade}

The gains of international trade are present in the model outlined above, but only in a rudimentary way. An increase in the available labor supply still shifts the average cost downward. This shift has implications for the number of varieties that are produced, which increases (see Equation 5: $L / l_{i}=N$ ), but has no impact on other elements in the model. Consumers gain from trade because they consume more varieties than before international trade was allowed.

More interesting results can be derived by introducing transport costs. This is certainly true from a New Economic Geography perspective because the relevance of economic geography crucially hinges upon the presence of positive transport costs; without transport costs geography does not matter. The combination of increasing returns to scale and transport costs implies that firms not only want to concentrate production in a single location (because of increasing returns to scale) but they also care where in space they locate production (because of the transport costs). Firms prefer to locate where demand for the variety they produce is relatively large. This interplay between increasing returns to scale, transport costs and demand has become known as the Home Market effect, which is also the basis for New Economic Geography literature. Our discussion of the Home Market effect is in two parts: the more than proportional production of the increasing returns sector in the larger market (the volume effect, Sect. 2.2), and the higher wages of the increasing returns sector in the larger market (the price effect, Sect. 2.3). The key issue is that with positive transport costs, the larger market offers location benefits that are absent in models that do not include transport costs. We introduce this difference as the two versions have important consequences for empirical tests of the model that are not always taken into consideration.

\subsection{The Home Market Effect as a Volume Effect}

Iceberg transportation costs have the advantage that transportation costs can be introduced without having to deal with a transportation sector (see for a discussion Fingleton and McCann (2007)). Assume the iceberg costs are $\tau \geq 1$; that is $\tau$ units have to be shipped in order for one unit to arrive in the other country. This raises the costs of imported varieties to $p \tau$. Demand for a domestic variety now comes from two sources: domestic demand (8a) and foreign demand (8b). From Eq. (2) it can be inferred that these two expressions are (where $*$ indicates Foreign variables):

$$
\begin{gathered}
x_{i}=\frac{p^{-\varepsilon}}{N p^{1-\varepsilon}+N^{*}(\tau p)^{1-\varepsilon}} \delta w L \\
x_{i}^{*}=\frac{(\tau p)^{-\varepsilon}}{N(\tau p)^{1-\varepsilon}+N^{*} p^{1-\varepsilon}} \delta w^{*} L^{*}
\end{gathered}
$$


Similar equations can be derived for the Foreign country. From the discussion following Eqs. (6) and (7) we know that output per firm is fixed and equal to $x$ in equilibrium.

Goods market clearing in each country for the increasing returns sector is provided for the Home country in Eq. (9a) and for the Foreign country in Eq. (9b).

$$
\begin{gathered}
X \equiv N x=\frac{N p^{-\varepsilon}}{N p^{1-\varepsilon}+N^{*}(\tau p)^{1-\varepsilon}} \delta w L+\frac{N(\tau p)^{-\varepsilon}}{N(\tau p)^{1-\varepsilon}+N^{*} p^{1-\varepsilon}} \delta w^{*} L^{*} \tau \\
X^{*} \equiv N^{*} x=\frac{N^{*}(\tau p)^{-\varepsilon}}{N p^{1-\varepsilon}+N^{*}(\tau p)^{1-\varepsilon}} \delta w L \tau+\frac{N^{*} p^{-\varepsilon}}{N(\tau p)^{1-\varepsilon}+N^{*} p^{1-\varepsilon}} \delta w^{*} L^{*} \tau
\end{gathered}
$$

Note the additional $\tau$ multiplication terms in both expressions and also note that the output level in both countries - for individual firms - is $x$. In Eq. (9a) part of the Home exports to Foreign melts during transportation, but it needs to be produced before it can melt, and similarly in Eq. (9b) for exports from Foreign to Home, hence the additional multiplication by $\tau$.

Assume first that there are no transport costs with respect to the homogeneous sector $H$ and second (as is standard in international trade theory) that labor is mobile between sectors but immobile between countries. It follows that wages in the $H$ sectors in both countries are identical, and because of perfect inter-sector labor mobility, also in the increasing returns sector. Equation (6) allows us to choose units such that $p=w=1$. This implies that we can simplify Eqs. (9a) and (9b) as follows (with $Z \equiv \tau^{1-\varepsilon}$, this term is known as the free - ness of trade ):

$$
\begin{aligned}
& \frac{x}{\delta}=\frac{1}{N+N^{*} Z} L+\frac{Z}{N Z+N^{*}} L^{*} \\
& \frac{x}{\delta}=\frac{Z}{N+N^{*} Z} L+\frac{1}{N Z+N^{*}} L^{*}
\end{aligned}
$$

We have two equations and two unknowns ( $N$ and $\left.N^{*}\right)$. In principle we have three possible cases (numbered $a, b, c$ ), namely: complete specialization in one of the two countries (cases a and b) and incomplete specialization (case c):
a. $N=0, N^{*}=\frac{\delta\left(L+L^{*}\right)}{x}$ from (9b')
b. $N=\frac{\delta\left(L+L^{*}\right)}{x}, N^{*}=0$ from (9a')
c. $N=\frac{\delta\left(L-Z L^{*}\right)}{(1-Z) x}, N^{*}=\frac{\delta\left(L^{*}-Z L\right)}{(1-Z) x}$ from (9a') and (9b').

Concentrating on the Home country we can distinguish between these three possibilities. If we introduce the following notation $s_{l}=L /\left(L+L^{*}\right)$ and $s_{N}=N /$ $\left(N+N^{*}\right)$, where $s_{l}$ is the labor share and $s_{N}$ the share of varieties or firms in Home, we arrive at: 


$$
s_{N}= \begin{cases}0 & s_{l} \leq \frac{Z}{(1+Z)} \\
\frac{\left((1+Z) s_{l}-Z\right)}{(1-Z)} & \text { for } \begin{array}{l}
\frac{Z}{(1+Z)}<s_{l}<\frac{1}{(1+Z)} \\
1
\end{array} \\
s_{l} \geq \frac{1}{(1+Z)}\end{cases}
$$

The first entry in Eq. (10) follows from combining case $a$ with case $c$ (where specialization of all increasing returns production in Foreign just becomes binding). Similarly, the last entry follows from combining cases $b$ and $c$. Finally, the middle entry follows from solving case number $c$. The implications are illustrated in Fig. 1.

What we see is that if the Home country is large (small) enough in terms of labor relative to Foreign, it will attract (loose) all increasing returns manufactures. What is important in our discussion of the Home Market effect is the slope of the curve in the area of incomplete specialization: $\frac{Z}{(1+Z)}<s_{l}<\frac{1}{(1+Z)}$. From Eq. (10) we know that the slope of the line-piece is $\frac{(1+Z)}{(1-Z)}>1$, which implies that the larger country in this area has a more than proportional share of varieties and hence firms compared to its share in labor. The reasoning is as follows. Suppose that from the point $(1 / 2,1 / 2)$ a Foreign firm (together with its workers) relocates to the Home country that now becomes the larger market (the reason why this might take place is not important). This increases the market by the amount of workers that move, but it also increases the spending power of existing consumers who no longer have to incur transport costs resulting from importing the variety. This 'double' increase in demand raises profits in the

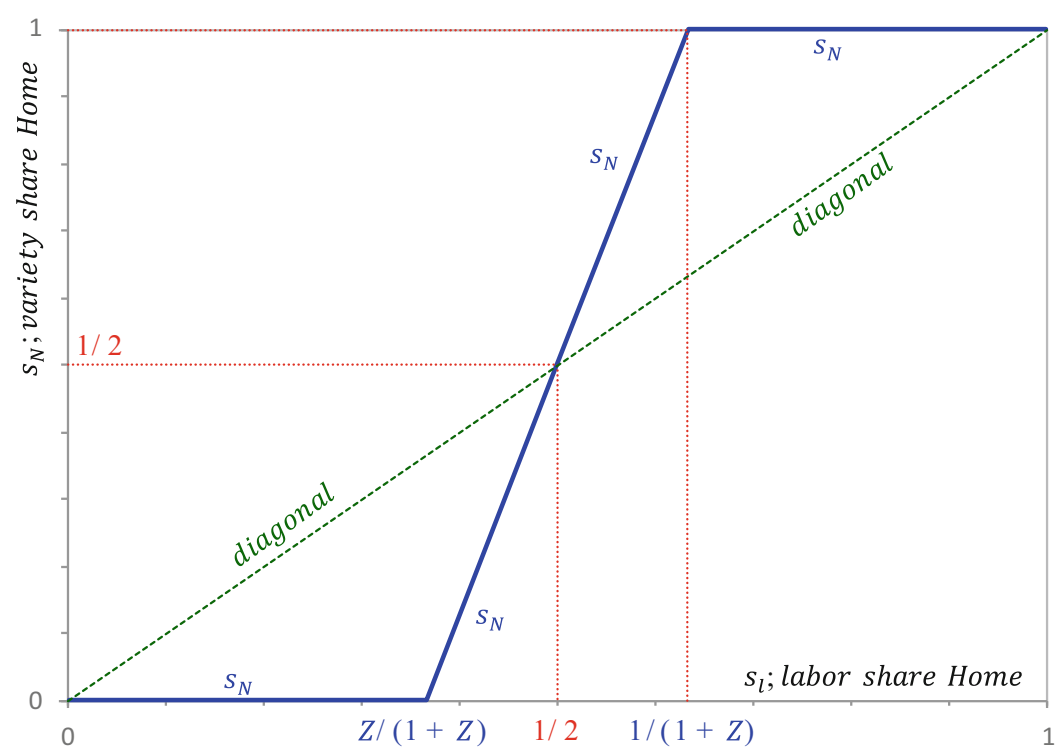

Fig. 1 Home Market Effect; the volume effect. (Source: Authors calculation, based on Helpman and Krugman (1985)). Note: picture drawn for $\tau=1.2$ and $\varepsilon=4$, so $Z=0.579$ 
larger market, and attracts more firms to the increasing returns sector. Points on the solid line indicate that the increase in the number of firms must be more than proportional than the number of workers (some workers come from the homogeneous sector) in order to restore equilibrium.

Why don't all firms move to the larger market in order to restore equilibrium? The reason is that additional firms also introduce more competition that reduces the (potential) profits in the larger market. To explore the thought experiment of making the Home market larger, it is instructive to look at the denominator of Eq. (8a). A firm moving from Foreign to Home makes the denominator smaller (as the variety no longer has to be imported), and this implies more local competition. This competition effect is stronger, the higher are transport costs (high transport costs shield a market from Foreign competition). So fewer firms have to move to re-establish equilibrium following the movement of a firm from Foreign to Home if transport costs are high (the slope of the line gets closer to the diagonal line).

To sum up, countries or regions with a relatively large demand for a good are host to a more than proportional share of production of that good. Against this Home market or market size effect, the competition effect acts to ensure that in equilibrium, and depending on the model's parameters (notably on the level of transport cost index $Z$ ), not all firms in the differentiated increasing returns to scale sector need to end up choosing the larger market as their location. From an empirical point of view, the model gives rise to a testable hypothesis with respect to international trade flows: countries with a relatively large Home market for variety $i$ ceteris paribus are net exporters of this variety. In the trade literature (see for example Davis and Weinstein (2003)), this implication of the Home Market effect has been subjected to a series of tests (see below).

Three other observations are relevant concerning the Home Market effect.

The first one is that the effect is quite sensitive to the underlying assumptions. If international trade in the homogenous good is also subject to transport costs, the Home Market effect ceases to exist (Davis 1998). Also, the analysis of the Home Market effect quickly gets quite complicated (or even muddled) for the case of more than two regions or countries.

The second observation is that in the example of Fig. 1, a large Home demand (here, a large $s_{l}$ ) leads to an influx of firms where the necessary labor to enable the additional production has to be released from the homogenous sector. Given that international labor mobility is still low (as we will see this is the main difference between Krugman (1980) and Krugman (1991)), the additional demand for labor by the firms in the differentiated increasing returns to scale sector in Home does indeed fully materialize in higher production because of an infinitely elastic inter-sector labor supply. If labor supply is not perfectly elastic at least part of the response in the larger market will be in the form of higher wages (Fujita et al. 1999, Equation (4.42); Head and Mayer 2006). As we will see next, with a less than elastic labor supply, a relatively large demand or a larger Home market then translates (partly) into higher wages.

A third and final observation is that demand across locations is given. This is a direct consequence of the fact that workers and hence consumers are immobile 
between locations. Any demand or market size differences are therefore exogenously given. What happens if one drops this assumption? What if not only firms but also (some) workers are mobile and can choose in which country or location they wish to live? Answering this question leads us to the center of New Economic Geography, but first we present another manifestation of the Home Market effect in terms of wages. The reason is that migration is determined by (real) wage differences between locations. So, we first need to derive an expression for (real) wages.

\subsection{The Home Market Effect as a Factor Price Effect}

In the example underlying Fig. 1, we (by construction) ignored any effect that market or demand size differences might have on wages. Labor was perfectly elastic between sectors but not between countries, which is the usual assumption in international trade theory. This enables us to focus on the number of varieties (firms). In Krugman (1991) an opposing case is introduced; the larger market does not attract more than a proportional share of firms, compared to its share in labor, but all benefits of a larger market now show up in terms of higher wages in the increasing returns sector.

Actually such a wage effect can already be seen as an outcome of the Krugman (1980) model, we only have to change one assumption: labor is not only immobile between countries, but now also immobile between sectors. The implications are that we no longer have factor price equalization and that the number of varieties (firms) is proportional to the given quantity of labor in the increasing returns sector (so by assumption the Home Market effect of the previous section is absent). The set-up of the model remains the same, but we can no longer take the steps to simplify Eqs. (9a) and (9b) to Eqs. (9a') and (9b'). At the same time it is true that location in the larger market offers benefits relative to location in the smaller market. Again, as in the previous section, location in the larger market implies that firms do not have to incur transport costs and that this increases the spending (real income) of consumers. How does it show up in this case? We can use Eq. (9a) to show this for the Home country (similarly for the Foreign country using Eq. (9b)). Note that as wages are not necessarily the same, prices also differ between countries. Furthermore, we have to be careful how to define income, $Y$ and $Y^{*}$, in this case (see below). Taking care of these aspects results in:

$$
\frac{(\varepsilon-1) \alpha}{\beta}=\frac{N p^{-\varepsilon}}{N p^{1-\varepsilon}+N^{*}\left(\tau p^{*}\right)^{1-\varepsilon}} \delta Y+\frac{N(\tau p)^{-\varepsilon}}{N(\tau p)^{1-\varepsilon}+N^{*}\left(p^{*}\right)^{1-\varepsilon}} \delta Y^{*} \tau
$$

In (11) we have again used the fact that in the model mark-up pricing together with the zero profit condition fixes the break-even output of firms (see the left hand side of Eq. (11), and the discussion following Eqs. (6) and (7)).

Using $p=\varepsilon \beta w /(\varepsilon-1)$ and $p^{*}=\varepsilon \beta w^{*} /(\varepsilon-1)$, we can rewrite Eq. (11) in terms of wages in the manufacturing sector (and do the same for the Foreign country): 


$$
\begin{aligned}
& w=\rho \beta^{-\rho}\left(\frac{\delta}{(\varepsilon-1) \alpha}\right)^{1 / \varepsilon}\left(Y P_{1}^{\varepsilon-1}+\tau^{1-\varepsilon} Y^{*} P_{2}^{\varepsilon-1}\right)^{1 / \varepsilon} \\
& w^{*}=\rho \beta^{-\rho}\left(\frac{\delta}{(\varepsilon-1) \alpha}\right)^{1 / \varepsilon}\left(Y^{*} P_{2}^{\varepsilon-1}+\tau^{1-\varepsilon} Y P_{1}^{\varepsilon-1}\right)^{1 / \varepsilon}
\end{aligned}
$$

Where $P_{1}^{1-\varepsilon}=N\left(\frac{w}{\rho}\right)^{1-\varepsilon}+N^{*}\left(\frac{\tau w^{*}}{\rho}\right)^{1-\varepsilon}$ and $P_{2}^{1-\varepsilon}=N\left(\frac{\tau w}{\rho}\right)^{1-\varepsilon}+N^{*}\left(\frac{w^{*}}{\rho}\right)^{1-\varepsilon}$ are price indices and $Y$ and $Y^{*}$ are the income levels generated in Home and Foreign, respectively.

These equations make sense in the following way. Wages in Home are higher if it has a large Home market in terms of real income $Y P_{1}$ or if it is located near a large Foreign market (large $Y^{*} P_{2}$ and low transport costs, or (equivalently a high free-ness of trade $\tau^{1-\varepsilon}$ ). The benefits of a large market are not reflected in a more than proportional share of firms relative to the labor share, but in higher wages.

\section{$3 \quad$ Adding Labor Mobility}

\subsection{Core New Economic Geography Model}

It is now only a small step to make the model a full general equilibrium model that includes labor mobility (see also Brakman and Garretsen (2009)). The only thing to add is the possibility of labor migration between regions. This implies that a region's market size becomes endogenous when migration is allowed to take place. In the 2-region setting of Krugman (1991) the equilibrium conditions of the model can be stated as follows:

$$
\begin{gathered}
Y=w L+0.5 L_{H} \\
Y^{*}=w^{*} L^{*}+0.5 L_{H} \\
w=\rho \beta^{-\rho}\left(\frac{\delta}{(\varepsilon-1) \alpha}\right)^{1 / \varepsilon}\left(Y P_{1}^{\varepsilon-1}+\tau^{1-\varepsilon} Y^{*} P_{2}^{\varepsilon-1}\right)^{1 / \varepsilon} \\
w^{*}=\rho \beta^{-\rho}\left(\frac{\delta}{(\varepsilon-1) \alpha}\right)^{1 / \varepsilon}\left(Y^{*} P_{2}^{\varepsilon-1}+\tau^{1-\varepsilon} Y P_{1}^{\varepsilon-1}\right)^{1 / \varepsilon} \\
P_{1}^{1-\varepsilon}=N\left(\frac{w}{\rho}\right)^{1-\varepsilon}+N^{*}\left(\frac{\tau w^{*}}{\rho}\right)^{1-\varepsilon} \\
P_{2}^{1-\varepsilon}=N\left(\frac{\tau w}{\rho}\right)^{1-\varepsilon}+N^{*}\left(\frac{w^{*}}{\rho}\right)^{1-\varepsilon}
\end{gathered}
$$




$$
\begin{gathered}
\omega=\frac{w}{P_{1}^{\delta}} ; \omega^{*}=\frac{w^{*}}{P_{2}^{\delta}} \\
\frac{d L}{L}=-\frac{d L^{*}}{L^{*}}=\eta(\omega-\bar{\omega}), \text { with } \bar{\omega}=\lambda \omega+\lambda^{*} \omega^{*}
\end{gathered}
$$

The model clearly builds (and even largely overlaps) with the international trade model of Sect. 2, but also includes some new elements of which interregional labor mobility is the most relevant one. Equations (13a) and (13b) are the income equations in the two regions or countries, Home and Foreign. The first term on the right hand side indicates income earned in the increasing returns sectors that earn wages $w$ and $w^{*}$ in Home and Foreign, respectively. We assume that labor (in the increasing returns sector) is mobile between countries but not between sectors. The distribution of labor in the homogeneous (agricultural) sector is given and does not change. Total labor supply in this sector is $L_{H}$ and we assume - just for simplicity that it is equally distributed over the two countries. There are no transport costs in this sector implying that wages earned in the homogeneous goods sector are equal in both regions, and we can use this sector as the numéraire sector, and wages in the increasing returns sector are relative to the wages in the homogeneous goods sector. It is important to note that we cannot do without this homogeneous goods sector in Krugman's (1991) core New Economic Geography model. It implies that even when labor in the increasing returns sector is completely agglomerated by being located in just one of the two regions, there is always a positive (residual) demand in the other region, and firms might want to re-locate to this region in order to get away from the stiffer competition in the larger region.

Equations (13c), (13d), (13e), and (13f) are already familiar from earlier sections. Equations $(13 \mathrm{~g})$ and $(13 \mathrm{~h})$ give the dynamics in the model. We define real income of a worker in the increasing returns to scale sector in Eq. (13g). It is simply wages divided by the price index of all the commodities consumed (including the homogenous good). As the increasing returns to scale sector comprises a share $\delta$ in the consumption basket, we want to correct for this in Eq. (13g). We also divide by the price in the homogeneous sector (raised to the power $1-\delta$, the share of the homogeneous goods sector), but this does not show up because the homogeneous good is the numéraire good (and the price equals one). Equation (13h) states that labour in the increasing returns sectors moves to the region with the highest real wage ( $\lambda$ is the share of mobile workers in the Home country). Of course, in the real world migration decisions are based on more than just real wage differences. The model gets quite complicated because if labor moves to (say) the Home country, this changes incomes [Eqs. (13a) and (13b)] which affects nominal wages [Eqs. (13c) and (13d)], and also the prices indices [Eqs. (13e) and (13f), see Brakman et al. (2019), Chap. 7 for details on the price indices]. This subsequently affects the migration decision itself. These effects are non-linear.

Given the key model parameters, most importantly the value of transport costs, the balance between the agglomeration forces (Home Market effect, Price Index effect) and the spreading forces (competition effect) we determine what the 
equilibrium spatial allocation will be. It turns out that the model has basically three (stable) equilibria: full agglomeration in Home or Foreign, and perfect spreading. Interestingly, the model is not only characterized by multiple equilibria but also by path dependency. Figure 2 illustrates the model. The so called Tomahawk diagram depicted in Fig. 2 shows that for low free-ness of trade $\tau^{1-\varepsilon}(=Z$ in the previous section), that is for high transport costs $\tau$, footloose labor is evenly spread between the two regions but if the free-ness of trade gets high enough, that is if transport costs get low enough, all footloose workers end up in either region 1 or 2 in equilibrium.

The solid lines indicate stable equilibria, the dashed lines indicate unstable equilibria. The arrows indicate in what direction the incentive for firms (and footloose labor) points, depending on the value of transportation costs.

What are the forces that determine interregional migration? Three forces matter in the Krugman (1991) model: the Price Index effect, the Home Market effect, and the Extent of Competition effect. The Price Index effect stimulates agglomeration in the larger market as fewer varieties have to be imported and this saves on transport costs. This effect is magnified by the Home Market effect discussed above. If the Home Market effect results in higher wages (see Sect. 3.1) it makes the larger market more attractive. These agglomeration effects are counteracted and diminished by the Extent of Competition effect, which acts as a spreading force. If a firm moves to the larger market the denominators in (9a) and (9b) become smaller, which reduces the demand for an individual firm. The more firms (and workers) there are in a region, the higher the level of competition will be.

The balance between these three forces determines the direction of the arrows in Fig. 2. For low values of transport costs (high values of the free-ness of trade) the competition effect is felt less as the price difference between markets become

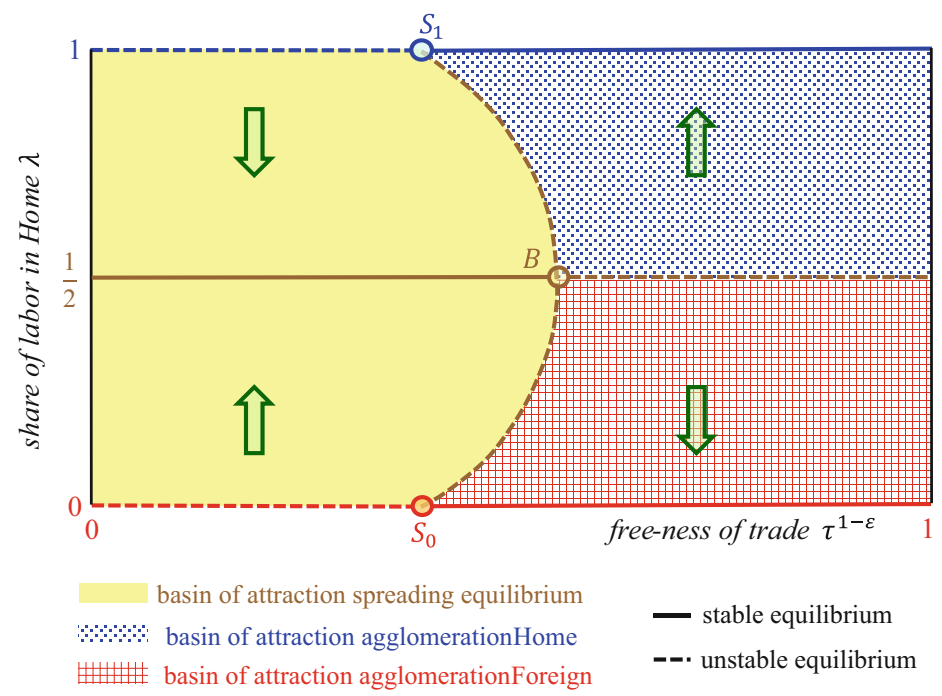

Fig. 2 The Tomahawk for the Krugman (1991) model. (Source: Brakman et al. 2019) 
smaller. Note from Fig. 2 that there is not a gradual change from one stable equilibrium to another, but instead a catastrophic change; the moment the balance tilts between these forces it is either full agglomeration in one region or the other. Starting from an initial situation of a low free-ness of trade (left part of $x$-axis in Fig. 2), the point at which this happens is the so called break point $B$; moving from high to low transportation costs, spreading is no longer a stable equilibrium (breaks) if transport costs are reduced further. One could also start with very low transport costs (high free-ness of trade) and then subsequently increase transport costs (lower the free-ness of trade) until agglomeration becomes unstable. This happens at the so called sustain points $S_{0}$ and $S_{1}$ in Fig. 2. Note that in the middle part of Fig. 2 there is some overlap as to the range of the free-ness of trade for the agglomeration and spreading equilibrium which indicates that the model is characterized by path dependency, see Brakman et al. (2019, Chap. 7) for further discussion.

\subsection{Model Extensions}

The model described in Sect. 3.1 states the essence of the New Economic Geography model as introduced by Krugman (1991). In the subsequent literature many additions have been incorporated in this framework. These extensions are often motivated to correct some of the more unlikely aspects of the model or to make the model more tractable.

\subsubsection{Intermediate Goods}

The model introduced above can be extended with an intermediate production sector. Assuming that labor is intra-regionally mobile, but inter-regionally immobile produces more realistic results than the extreme outcome as described in Fig. 2. Economic integration in this case, results in real wage convergence between regions rather than divergence. The reason for this is that the peripheral region becomes more attractive for manufacturing production as transport cost decline, because wage differences start to dominate transportation costs (which decline during economic integration). Most importantly, however, is the extension introduced by Puga (1999). The model introduced above predicts that small changes in the parameter values could result in sudden and dramatic changes (see the sustain and break points in Fig. 2) which seems unrealistic in practice. Puga (1999) extends the intermediate production model and assumes that the numeraire sector is no longer characterized by constant returns to scale, but instead by diminishing returns. This implies that pulling workers out of the homogeneous sector raises marginal productivity and nominal wages in this sector. This adds an additional spreading force into the model preventing a bang-bang solution as in the standard model. Puga (1999) shows that this additional force combined with the assumptions in Krugman and Venables (1995), and Venables (1996) are so strong that instead of the Tomahawk as depicted by Fig. 2, a bell-shaped curve appears, which suggests a more gradual change from full agglomeration to complete spreading. This aspect of the Puga (1999) model makes it a preferred model in empirical research (see below). 


\subsubsection{Factors of Production}

Another extension is to allow for more factors of production. One can assume, for instance, that manufacturing production uses high-skilled and low-skilled labor in production. This makes the model more in touch with reality. A surprising side effect is that the model becomes more tractable than in the standard case. If high skilledlabor is used in the fixed part of production, ( $\alpha$ in Eq. (3)), and low-skilled labor in variable-cost part of manufacturing production $(\beta$ in Eq. (3)), but also in the production of the homogeneous sector, we no longer have to solve for nominal wages (which also can be normalized), but only for high-skilled wages. The solution is relatively straightforward. So, besides introducing the more factors of production we can now derive explicit solutions. This is not the only change to the basic model that results in analytical solutions. Ottaviano, Tabuchi, and Thisse (2002), for instance, drop the CES demand structure and introduce a quasi-linear demand structure.

\subsubsection{Heterogeneous Firms}

The Melitz 2003revolution has also entered New Economic Geography. Firms in the standard models are all the same according to their cost structure, see Eq. (3). However, Baldwin and Okubo (2006) introduce productivity differences between firms. They show that firms line up for reallocation from a small to a large market in order of firm productivity levels; more productive firms can already relocate at transportation levels that would imply a loss for less productive firms. Models like these are important for empirical research as they point towards an empirical complication: do larger markets benefit from 'agglomeration economies' or from the fact that they are Home to the more productive firms?

\section{$4 \quad$ Empirical Testing}

Can we test the main implications of New Economic Geography? This seems a simple question, but it has turned out that this question is surprisingly difficult to answer. The model has interesting consequences, but a combined test of the main or all aspects is still missing. Head and Mayer (2004, p. 2616) already identified five main characteristics - slightly restated by us below and compressed into three main testable implications - that are special for New Economic Geography and could be tested to explain the facts implied by Figs. 1 and 2 (Brakman et al. 2019, Chap. 9):

(a) The Home Market Effect: large regions will be host to a disproportional share of the imperfectly competitive industry. Such large markets are therefore, net exporters of industries characterized by increasing returns to scale. As we discussed at some length in Sect. 2, there are also two other possible testable implications from this effect:

(a1) The volume version (recall Fig. 1): a large market potential induces factor inflows from the small to the large market. Footloose factors of production 
will be attracted to those markets that pay relatively high real factor rewards. This leads to a process of circular causality.

(a2) The factor price version (Eqs. 12a and 12b): a large market potential raise local factor prices in the core relative to the periphery. An attractive market with a strong Home Market effect will increase demand for factors of production and this raises factor rewards.

(b) Shock sensitivity: as we discussed with Fig. 2, changes in the economic environment can trigger drastic and permanent changes in the spatial distribution of economic activity.

(c) At some critical level of transport or trade costs, and again see Fig. 2, a further reduction in transport costs induces agglomeration by relocation of the footloose factors of production. This implies that more economic integration should at some point lead to (more) agglomeration of the footloose activities and factors of production.

Characteristics (a1) and (a2) describe the consequence for factors of production or factor prices once the Home Market effect is established. As explained in Fujita et al. (1999, p. 57), the equilibrium of the Krugman (1991) model implies the following equation: $\frac{d Y}{Y}=\gamma_{1} \frac{d w}{w}+\gamma_{2} \frac{d L}{L}$, where $Y$ is total demand for the footloose sector, $w$ is the nominal wage rate in this sector, and $L$ is employment in this sector, while $\gamma_{1}$ and $\gamma_{2}$ are parameters. Note, that this equation also illustrates why the findings on the Home Market effect show a highly variable pattern of estimated coefficients: both wages and employment changes should be accounted for, not only employment changes as in the strict version of the Home Market effect. It shows that an increase in the demand $Y$ for the goods from the footloose sector not only causes employment changes (the volume version of the Home Market effect), but also induces wage $w$ changes (the factor price version of the Home Market effect).

In a series of papers, Davis and Weinstein (2003) have developed an empirical methodology that enables them "to distinguish a world in which trade arises due to increasing returns as opposed to comparative advantage" (Davis and Weinstein, 2003, p. 3). In general they find some support for the volume version of the Home Market effect. As shown in Brakman, Garretsen and Schramm (2006), however, both effects are typically at work. On balance, it appears that the wage channel is the main route towards spatial equilibrium (Head and Mayer, 2006). This explains also why most empirical work has focused on the wage Eqs. (13c) and (13d). Despite the empirical evidence that supports the volume or factor price version of the Home Market effect, the question remains whether this evidence is a test of New Economic Geography as such; they are also a characteristic of standard trade models. We will return to this question at the end of the present section.

One of the key elements of New Economic Geography is the shock sensitivity. As illustrated by Fig. 2, small changes in parameters (in casu, the level of transport costs) can (but need not) have big consequences. It implies for instance that a small change in economic integration could lead to spectacular changes in the spatial distribution of economic activity. If small changes already can have large effects, one 
would be inclined to think that permanent effects in the spatial distribution of economic activity can be found after large changes. The key issue is whether one can come up with real world examples of a large, temporary and exogenous shock that can act as a testing ground for the shock sensitivity hypothesis. In a seminal paper, Davis and Weinstein (2002) use the case of the allied bombing of Japanese cities during World War II (WW II) as an example of such a shock. Brakman, Garretsen, and Schramm (2004) apply the Davis and Weinstein (2002) approach to the case of the allied bombing of German cities during WW II. In both studies the question is the same: did individual cities return to their initial, pre-war growth path after WW II? The break-up of Germany in 1949 in the Federal Republic of Germany FRG (West Germany) and the German Democratic Republic GDR (East Germany) and the subsequent re-unification of the two Germanies in 1990 after the fall of the Berlin Wall is another example of a large, temporary (40 year) shock. Redding and Sturm (2008) use this shock to test whether West-German border cities (close to the FRG-GDR border) experienced a substantial decline compared to non-border cities in West Germany. The evidence of these studies is somewhat mixed. Davis and Weinstein (2002) do not find evidence of long term effects, whereas the other studies - on Germany - do find such effects. In general it seems that economies show some shock sensitivity. Again, and notwithstanding this evidence on shock sensitivity, the ultimate question for our present purposes is whether these studies do provide a real test of New Economic Geography as such. Note for instance that the New Economic Geography model as depicted by Fig. 2 allows for shocks that can have permanent and non-permanent effects. Also, it is clear that New Economic Geography is not the only location or spatial model to predict that shocks can alter the spatial equilibrium allocation of economic activity.

Finally, New Economic Geography models predict that changes in transportation costs could result in changes in the degree of agglomeration through the relocation of the mobile factors of production. To this end, we essentially need the full model, as described in Sect. 3. The long-run equilibrium equation relates migration to real wage differences, which are determined in the model. For empirical research this is a challenging consequence of the model. First of all we have to find out where we are in terms of for instance Fig. 2. Is the economy that we are looking at initially to the left or to the right of the break point? This is important, because we like to know what happens if transportation costs change. In real world applications, however, we deal with a multi-region world and implicitly confront this multi-region model with break-points from the Tomahawk diagram in a 2-region setting, which is problematic. Similar analytical solutions for break-points in a multi-region setting $(n>2)$ only exist if all regions are at equal distance from each other. This assumption effectively means that the actual geography (where regions are located on a map) does not play a role, and thus that space is neutral in that sense. Any real world application clearly violates this assumption.

How should we proceed to arrive at more conclusive evidence for our empirical hypothesis on transportation or trade cost induced agglomeration? One option is to drop the 2-region model, with its analytical solutions, and instead use multi-region model simulations in which key equations are based on multiregional estimates of 
Eqs. (13c) and (13d). In Bosker et al. (2010) this is the preferred option. They show that, in a qualitative sense, the multi-region non-neutral space model gives rise to the same conclusions as the simple 2-region version of the Puga (1999) model, that is, the results show that the 2-region model carries over in the multi-region case. Given this result, the answer to the question, "where on these curves are we?" can be answered in a simulation setting. Repeated simulations, using the estimated wage curves for different values of transportation costs, allow us to construct a multiregion version of Fig. 2. Confronting this curve with actual estimates for transportation costs, gives us an idea where on the curve we are, and in what direction the economy is moving; towards further agglomeration or further spreading. But it is clear that evidence based on simulations is not the same thing as evidence based on actual estimations, while using the structural equations of the model and using real data, of the third New Economic Geography hypothesis.

How convincing is the empirical evidence for the New Economic Geography studies related to the three empirical hypotheses that were outlined at the beginning of this section? In addition to the comments made above for each of the hypotheses four general problems for empirical confirmation of the geographical economics model stand out (see also Redding (2010)):

(i) Studies are not only consistent with geographical economics models but also with other theories of trade and location (the Home Market effect can, for instance, also be found in other trade models, see also discussion in Fingleton and Fischer (2010));

(ii) Applying two region New Economic Geography models like Krugman (1991) to a multi-region world makes conclusive testing difficult or even outright impossible;

(iii) Causality: are the empirical observations caused by New Economic Geography forces or not? The empirical evidence indicates that wages (left hand side of the empirical specification of Eqs. (13c) and (13d)) are related to measures of market access. An important problem is whether this is a causal relation. Higher wages in regions with good market access may be caused by better institutions in surrounding regions or locational fundamentals instead of New Economic Geography forces, and the measures of market access might simply capture these more fundamental causes. This issue is more problematic for testing the Home Market effect (hypothesis 1) than for shock sensitivity tests (hypothesis 2, where cause and effect are more clearly distinguished);

(iv) Using micro data: virtually all empirical New Economic Geography work is based on the representative firm and consumer framework and ignores the extensive micro data sets that have become available over the past years. Using these data (as in the urban economics literature), in combination with state of the art empirical methods like IV, diff-in-diff or a regression discontinuity design make it possible to determine if the agglomeration effects in the core are based on selection effects (truncation of the distribution) or agglomeration as such (rightward shift of the distribution), see Combes et al. (2008) or De La Roca and Puga (2017). 
A way forward is the development of the so called 'quantitative spatial economics' approach where the key ingredients from the New Economic Geography model are combined with the basic determinants of household and firm location choices from other approaches, notably urban economics, in a rather pragmatic way that lends itself more easily to empirical and policy applications (see Redding and RossiHansberg 2017). Another fruitful avenue for empirical (and policy) research us the deployment of multi-region versions of, at their very core, New Economic Geography type models to simulate or mimic the impact of large scale (infrastructure) investments or shocks, see for instance Donaldson and Hornbeck (2016) or Donaldson (2018).

\section{$5 \quad$ Policy Consequences}

The New Economic Geography framework is widely used to discuss policy implications of (local or national) interventions. This holds, for example, for many (regional) studies performed on behalf of the European Union and for the recent World Development Report 2009 by the World Bank (2008). A good summary of the six general policy conclusions based on the New Economic Geography model is provided by Ottaviano (2003) or Brakman et al. (2019, Chap. 11), for a more extensive treatment of these points see Baldwin et al. (2003):

- Regional side effects. One of the fundamental insights from New Economic Geography is that regions are connected and cannot be studied in isolation. Regional policy measures that, for example, affect economic integration have consequences for all regions, not only the region at which the measure is aimed. Effects of regional policies are economy wide.

- Trade interaction effects. Outcomes of the model depend crucially on initial levels of economic integration. A similar policy measure can have different effects, depending on the initial position of the economy (see Fig. 2).

- Lock-in effects. Temporary measures can have permanent effects. Suppose that a temporary subsidy takes an economy over the break point in Fig. 2. It is then possible that a new long run stable equilibrium is reached. The economy will remain there even when the subsidy is ended. Also history matters. If an economy finds itself in a stable equilibrium strong policy measures might be needed in order to establish another equilibrium, in other words 'history matters.'

- Selection effects. Figure 2 indicates that if transport costs are low, two stable equilibria are possible. Selecting one of the possibilities can have huge consequences from a welfare perspective. For example, the immobile workers in the core region benefit from being located in the core, but policy makers have to make up their mind that they indeed give welfare in the core region a greater weight in social welfare considerations than in the peripheral regions.

- Threshold effects. Policies measures can seem ineffective. The reason is that measures should take an economy over the breakpoint in order to become effective. 
- Coordination effects. New Economic Geography models are characterized by multiple equilibria. Especially in the overlap area in Fig. 2 expectations about the future of the economy can be important. If policy makes can convince firms/ workers to relocate, this will start a self-sustaining move to a new equilibrium. A subsidy might take an economy towards a new equilibrium, but if policy makers can convince workers and firms that a specific region is the place-to-be, a subsidy is not required.

The list suggests that a world characterized by New Economic Geography offers policy makers many attractive options. However, some qualifications are in order. First of all which New Economic Geography model describes the world best; the stylized model depicted in Fig. 2, or one of the models that are extensions of this Fig. 2 model? The model in Fig. 2 is to a large extent driven by a few parameters and it is highly unlikely that the real world can be described by only those few parameters, which are most likely different for all sorts of economies or periods (Combes 2011). Furthermore, in general core regions are always better off than peripheral regions. The Tomahawk Fig. 2 suggests that it is always possible, with the right measure, to pick a preferred equilibrium. Neary (2001) strongly argues against this 'picking equilibria' role for the government, because, as we concluded at the end of the previous section, the empirical evidence for New Economic Geography is still too weak (see above), and that such a policy would bear the risk of strategic, and wasteful, rent seeking behavior from competing regions. Still we think that one very strong policy measure results from New Economic Geography; regions are not free floating islands in space, but they are spatially interdependent. All too often regional policies are addressed to deal with a specific regional issue - like low wages, lack of employment, etc - and deal with such a region as if it is an island in space. Policy measures can have unexpected results. An investment in, for example, the regional infra-structure in this peripheral region might not stimulate growth in the periphery, but instead might strengthen the position of the core region because economic integration further strengthens the position of the core (see Fig. 2). This is probably - in a qualitative sense - one of the most important policy conclusions that can be derived from New Economic Geography. Indeed, this basic notion underlies recent policy-oriented work in the so-called quantitative spatial economics approach where "New Economic Geography style" spatial interdependencies are one of the key drivers of locational choices of economic agents and where the impact of (policy induced) large structural changes on those choices is analysed (see for instance, in a urban and intra-national, setting, Redding and Sturm (2016) or Heblich et al. (2018) and, in an inter-national setting, Desmet et al. (2018)).

\section{Conclusions}

We briefly discussed the structure of the New Economic Geography models to argue that the New aspect of this type of model is endogenizing economic size of a location. The "Economic" aspect of the name refers to the economic tools used, 
while the "Geography" part focuses on the crucial role of spatial interdependencies through transport and interaction costs. We then turn to the main empirical implications of New Economic Geography as summarized in a number of empirical characteristics. Despite the surge in empirical research in this area e a number of crucial problems with empirically testing the New Economic Geography models remains. We list four of these, namely (i) some effects can also be explained by other models in spatial economics at large, (ii) most tests in a multi-region world are only loosely based on a two-region basic model, (iii) despite the rise of the application of more sophisticated empirical methods in recent years causality problems are still rarely adequately addressed, and (iv) we need to integrate locational phenomena at different scales by continuing the trend to use more micro data. In view of our discussion of these shortcomings, the main policy implications (as discussed in Sect. 5) are still mostly qualitative, thus lacking a solid quantitative basis in most applied work. Here our money is on the latest incarnation of New Economic Geography, quantitative spatial economics (Redding and Rossi-Hansberg 2017), to take over the mantle as the most promising approach in mainstream economics to analyze the causes and consequences of location choices in a setting where spatial linkages matter.

\title{
$7 \quad$ Cross-References
}

\author{
Classical Contributions: Von Thünen and Weber \\ Factor Mobility and Migration Models \\ - Interregional Trade: Models and Analyses \\ - New Economic Geography and the City \\ Path Dependence and the Spatial Economy: A Key Concept in Retrospect and \\ Prospect \\ - Schools of Thought on Economic Geography, Institutions, and Development
}

Acknowledgements This chapter is partially based on earlier work by the authors (corresponding Author: Charles van Marrewijk). We do not give detailed references to our own work but readers interested in further details can consult our book on urban and geographical economics (Brakman et al. 2019) for more extensive and detailed discussions and references, see in particular chapters 7,8 , and 9 .

\section{References}

Baldwin R, Okubo T (2006) Heterogeneous firms, agglomeration and economic geography: spatial selection and sorting. J Econ Geogr 6(3):323-346

Bosker M, Brakman S, Garretsen H, Schramm M (2010) Adding geography to the new economic geography; bridging the gap between theory and empirics. J Econ Geogr 10(6):793-823

Brakman S, Garretsen H (2009) Trade and geography: Paul Krugman and the 2008 Nobel prize in economics. Spat Econ Anal 4(1):5-23

Brakman S, Heijdra BJ (eds) (2004) The monopolistic competition revolution in retrospect. Cambridge University Press, Cambridge 
Brakman S, Garretsen H, Schramm M (2004) The spatial distribution of wages: estimating the Helpman-Hanson model for Germany. J Reg Sci 44(3):437-466

Brakman S, Garretsen H, Schramm M (2006) Putting new economic geography to the test: free-ness of trade and agglomeration in the EU regions. Reg Sci Urban Econ 36(5):613-636

Brakman S, Garretsen H, Van Marrewijk C (2019) A spiky world: an introduction to urban and geographical economics. Cambridge University Press, Cambridge

Combes P-P (2011) The empirics of economic geography: how to draw policy implications? Rev World Econ 147(3):567-592

Combes P-P, Duranton G, Gobillon L (2008) Spatial wage disparities: sorting matters! J Urban Econ 63(2):723-742

Davis DR (1998) The Home Market, Trade and Industrial Structure. Am Econ Rev 88:1264-1277

Davis DR, Weinstein DE (2002) Bones, bombs and breakpoints: the geography of economic activity. Am Econ Rev 92(5):1269-1289

Davis DR, Weinstein DE (2003) Market access. Economic geography and comparative advantage: an empirical assessment. J Int Econ 59(1):1-23

De La Roca J, Puga D (2017) Learning by working in big cities. Rev Econ Stud 84:106-142

Desmet K, Nagy DK, Rossi-Hansberg E (2018) The geography of development. J Polit Econ 126:903-983

Dixit A, Norman V (1980) Theory of international trade. Cambridge University Press, Cambridge, UK

Dixit A, Stiglitz J (1977) Monopolistic competition and optimum product diversity. Am Econ Rev 67(3):297-308

Donaldson D (2018) Railroads of the Raj: estimating the impact of transportation infrastructure. Am Econ Rev 108(4-5):899-934

Donaldson D, Hornbeck R (2016) Railroads and American economic growth: a "market access" approach. Q J Econ 131(2):799-858

Feenstra RC (2016) Advanced international trade: theory and evidence, 2nd edn. Princeton University Press, Princeton

Fingleton B, Fischer MM (2010) Neoclassical theory versus new economic geography: competing explanations of cross-regional variations in economic development. Ann Reg Sci 44(3):467-491

Fingleton B, McCann P (2007) Sinking the iceberg? On the treatment of transport costs in new economic geography. In: Fingleton B (ed) New directions in economic geography. Edward Elgar, Cheltenham, pp 168-204

Fujita M, Krugman PR, Venables AJ (1999) The spatial economy; cities, regions, and interantional trade. MIT Press, Cambridge

Glaeser E (2008) Cities, agglomeration, and spatial equilibrium. Oxford University Press, Oxford, UK

Grubel HG, Lloyd P (1975) Intra-industry trade: the theory and measurement of international trade in differentiated products. Macmillan, London

Head K, Mayer T (2006) Regional wage and employment responses to market potential in the EU. Reg Sci Urban Econ 36(5):573-594

Heblich S, Redding SJ, Sturm DM (2018) The making of the modern metropolis: evidence from London. CEPR discussion paper 13170, London

Helpman E, Krugman P (1985) Market structure and foreign trade: increasing returns, imperfect competition, and the international economy. MIT Press, Cambridge, MA

Henderson VJ (1974) The sizes and types of cities. Am Econ Rev 64:640-656

Krugman P (1979) Increasing returns, monopolistic competition and international trade. J Int Econ 9(4):469-479

Krugman P (1980) Scale economies, product differentiation, and the pattern of trade. Am Econ Rev 70(5):950-959

Krugman PR, Venables AJ (1995) Globalization and the inequality of nations. Q J Econ 110:857-880

Krugman P (1991) Increasing returns and economic geography. J Polit Econ 99:483-499 
Melitz MJ (2003) The impact of trade on intra-industry reallocation and aggregate industry productivity. Econometrica 71(6):1695-1725

Ottaviano GIP (2003) Regional policy in the global economy: insights from the new economic geography. Reg Stud 37(6-7):665-673

Puga D (1999) The rise and fall of regional inequalities. Eur Econ Rev 43(2):303-334

Redding SJ (2010) The empirics of new economic geography. J Reg Sci 50(1):297-311

Redding S, Rossi-Hansberg E (2017) Quantitative spatial economics. Ann Rev Econ 9(1):21-58

Redding SJ, Sturm DM (2008) The costs of remoteness: evidence from German division and reunification. Am Econ Rev 98(5):1766-1797

Redding SJ, Sturm DM (2016) Estimating neighborhood effects: evidence from war-time destruction in London, mimeo, see http://www.princeton.edu/ reddings/papers/LWW2-9Mar16.pdf

World Bank (2008) World development report 2009. World Bank, Washington, DC

Venables AJ (1996) Equilibrium Locations of Vertically Linked Industries. Int Econ Rev 37:341-359

\section{Further Reading}

Baldwin R, Forslid R, Martin P, Ottaviano GIP, Robert-Nicoud F (2003) Economic geography and public policy. Princeton University Press, Princeton

Brakman S, Garretsen H, Van Marrewijk C (2019) A spiky world: an introduction to urban and geographical economics. Cambridge University Press, Cambridge

Combes P-P, Mayer T, Thisse J-F (2008) Economic geography. Princeton University Press, Princeton

Fujita M, Krugman PR, Venables AJ (1999) The spatial economy; cities, regions, and international trade. MIT Press, Cambridge, MA

Head K, Mayer T (2004) The empirics of agglomeration and trade. In: Henderson V, Thisse J-F (eds) Handbook of regional and urban economics, vol IV. North Holland, Amsterdam, pp 2609-2665

Neary JP (2001) Of hype and hyperbolas: introducing the new economic geography. J Econ Lit 39(2):536-561 